А.А. Гайворонская

\title{
ПСИХОСЕМАНТИКА ЭКСТРЕМИЗМА
}

\begin{abstract}
Аннотация. В предлагаемой статье предпринята попытка теоретического обоснования психосемантики экстремизма. Психосемантика - это область психологической науки, которая изучает картину мира индивидуального или коллективного субъекта. Феномен экстремизма связан с изучением важнейших компонентов ценностно-смысловых ориентаций, установок, стереотипов различных социальных, возрастных или этнических групп. Мы полагаем, что существует психологическая (семантическая) структура феномена экстремизма, сформированная различными типами значений, категориальными структурами, «классифицирующими» этот феномен, его виды на разных уровнях взаимодействия с субъектом или группой.

Психосемантические методы, изучающие феномен экстремизма, направлены на реконструкцию имплицитных теорий личности описывающих этот феномен (соединение исследуемого значения с другими значениями, системами значений, выделение и интерпретация среди этих связей наиболее существенных).

Научная новизна состоит в том, что было выдвинуто предположение о существовании психологической (семантической) структуры феномена экстремизма, которая может быть сформирована различными типами значений, категориальными структурами, "классифицирующими» этот феномен. Также была предложена имплицитная модель психосемантики экстремизма.

Выводы: психосемантика экстремизма способствует более тщательному изучению сущностных характеристики феномена экстремизма, а именно, как системы значений выражаясь в различных контекстах, проявляются на бессознательном и осознанном уровне применительно к феномену экстремизма и его видам. Ключевые слова: психосемантика, экстремизм, картина мира, имплицитные теории личности, категориальные структуры, реконструирование, модели, системы значений, способы категоризации, семантические пространства.
\end{abstract}

$\mathrm{B}$ настоящее время существует большое количество исследований, так или иначе связанных с психосемантикой и ее экспериментальными методами. Основателем психосемантики является В.Ф. Петренко, который один из первых проводил психосемантические исследования обыденного сознания. Под обыденным сознанием понимают совокупность представлений, знаний, установок, стереотипов, основывающихся на непосредственном повседневном опыте, так называемом донаучном знании ${ }^{1}$. Донаучное знание (наблюдение, опыт, представления) Дж. Брунер и Р. Тагиури обозначили как «имплицитная» теория (модель) личности².

Словарь / Под ред. М.Ю. Кондратьева // Психологический лексикон. Энциклопедический словарь в 6-ти т. / Ред.-сост. Л.А. Карпенко; Под общ. ред. А.В. Петровского. М.: ПЕР СЭ, 2006. 176 c.

2 Bruner J.S., Tagiuri R. The perception of people // Handbook of Social Psychology. N.J., 1954.
Плюрализм истины, множественность различных культурно-исторических моделей мира находят отражение в работах В.Ф. Петренко, это идеи конструктивизма - конструктивная природа человеческого восприятия, роль индивидуальных конструктов в познании и понимании мира, языковая и культурно-историческая опосредованность познавательных процессов, идеи множества способов описания событий и относительности истин $^{3}$. Термин «психосемантика» принадлежит Ч. Парфетти и образован из двух частей: психо-общая часть со словом психология (om греч.psyche душа) и семантика (от греч. sēmaino - «указываю», «означаю»), где семантика - это раздел семиотики, изучающий знаковые системы как средства выражения смысла ${ }^{4}$. Психосемантика - это

Петренко В.Ф. Многомерное сознание: психосемантическая парадигма. М.: Новый хронограф, 2009. 440 с.

4 Perffetti Ch. Psychosemantics: Some cognitive aspects of structural meaning // Psychol. Bull., 1972, v. 78, N 4, pp. 241-259. 


\section{Психология масс}

область психологической науки, которая изучает картину мира индивидуального или коллективного субъекта. Экспериментальная психосемантика изучает генезис, строение и функционирование системы значений, опосредствующей процессы восприятия, мышления, памяти, принятия решений ${ }^{5}$. В системы значений входят слова, знаки, символы, изображения, выразительные движения, формы ритуального поведения и т.д. А.Н. Леонтьев для описания систем значений субъекта предложил понятие «образ мира» ${ }^{6}$ В системах значений объединяются когнитивные и аффективно-мотивационные единицы деятельности, способствуя формированию образа мира. Д.А. Леонтьев понимает под образом мира мировоззрение, в котором содержатся «структурированные представления об общих закономерностях, которым подчиняется мир, общество и человек, а также о характеристиках идеального, совершенного мира, общества и человека» ${ }^{7}$. Образ мира близок к понятию картина мира. Картина мира - это понятие, соединяющее в себе различные модели восприятия мира. В.П. Петренко полагает, что картина мира определяет поведение человека, соединяет когнитивные, ценностные, эмоциональные аспекты. «Картина мира субъекта раскрывается через становление самого субъекта в широком контексте его смыслообразования» ${ }^{8}$. В задачи психосемантики входит исследование различных форм существования значений в индивидуальном и групповом сознании (образы, символы, символические действия, а также знаковые, вербальные формы), а также изучение общепсихологических аспектов процесса категоризации. Таким образом, психосемантика, раскрывая оценки тех или иных социальных явлений (способы категоризации) выявляет скрытые (неосознанные) процессы, оказывающие влияние на поведение субъекта(ов).

\footnotetext{
Словарь практического психолога / Сост. С.Ю. Головин. Минск: Харвест; 1998. 800 с.

6 Леонтьев А.Н. Образ мира // Леонтьев А.Н. Избранные психологические произведения: В 2-х т. М., 1983. С. 251-261.

7 Леонтьев Д.А. Мировоззрение как миф и мировоззрение как деятельность // Менталитет и коммуникативная среда в транзитивном обществе / Под ред. В.И. Кабрина и О.И. Муравьевой. Томск: Томский государственный университет, 2004. С. 11-29.

8 Петренко В.Ф. Психосемантические аспекты картины мира субъекта // Психология. Журнал Высшей школы экономики, 2005. Т. 2. № 2. С. 3-23.
}

Объектом психосемантики являются системы значений.

В концепции Л.С. Выготского значение выступает внутренней структурой знаковой операции с динамическим, процессуальным характером ${ }^{9}$ Для А.Н. Леонтьева значение это то, «что открывается в предмете или явлении объективно - в системе объективных связей, отношений, взаимодействий» ${ }^{10}$. Значение, личностный смысл и чувственная ткань образуют сознание. А.Н. Леонтьев подчеркивает двойственную природу значения. С одной стороны, значение выступает как единица общественного сознания, с другой - как образующая индивидуального сознания. В.Ф. Петренко дает определение значения с позиций конструктивисткой парадигмы, где ключевое слово это модель. Нельзя не согласиться со А.Г. Шмелевым, который считает, что значение является связующим звеном между психологией познавательных процессов и психологией личности и помогает одновременно раскрывать функциональный (поведенческий) смысл явлений психического отражения и психологический (субъективный) смысл явлений деятельности (см. табл. 1).

Предмет психосемантики - это способы категоризации систем значений, их моделирование. К способам категоризации относится обобщение, типизация опыта. Обобщается то, что субъект видит, делает, о чем размышляет. Осмысление действительности - это упорядочивание ее в своем представлении, установление отношений, существующих между вещами, явлениями, процессами. За категориями стоят повседневные понятия. Есть категории, которыми пользуются все субъекты, а есть специфические характерные только для отдельных субъектов. Обыденное сознание применяет базовый (средний) уровень, который не требует специальных знаний об объектах и легко усваивается. Представляя собой систему, категории связаны друг с другом, при этом категории имеют сложную семантическую организацию. В частности, В.Ф. Петренко полагает, что категории выступают в качестве базисных структур человеческого сознания и задают «концептуальную рамку» восприятия мира, в контексте которой строятся «имплицит-

\footnotetext{
9 Выготский Л.С. Собрание сочинений: В 6-ти т. Т. 6. Научное наследство / Под ред. М.Г. Ярошевского. М.: Педагогика, 1984. C. 160 .

10 Леонтьев А.Н. Избранные психологические произведения: В 2-х т. Т. І. М.: Педагогика, 1983. С. 240.
} 
Эволюция взглядов раскрывающих сущность понятия «значения»

\begin{tabular}{|c|c|}
\hline Авторы & Значение \\
\hline Л.С. ВыготскиЙ & $\begin{array}{l}\text { Значение - есть устойчивая система обобщений, стоящая за словом, одинаковая для всех людей, } \\
\text { причем эта система может иметь разные глубину, обобщенность, широту охвата обозначаемых им } \\
\text { предметов, но обязательно сохраняет неизменное «ядро» - определенный набор связей. }\end{array}$ \\
\hline А.Н. Леонтьев & $\begin{array}{l}\text { Значение - обобщенное отражение действительности, выработанное человечеством и зафикси- } \\
\text { рованное в форме понятия, знания или даже умения как обобщенного «образа действия», нормы } \\
\text { поведения и т. д.»**. }\end{array}$ \\
\hline В.Ф. Петренко & $\begin{array}{l}\text { Значение - обобщенная идеальная модель объекта в сознании субъекта, в которой зафиксированы } \\
\text { существенные свойства объекта, выделенные в совокупной общественной деятельности***. }\end{array}$ \\
\hline А.Г. Шмелев & $\begin{array}{l}\text { 1) Значение - репрезентативная единица; системная организация значений репрезентирует субъекту } \\
\text { тройственный морфизм предметов, операций и аффективно-мотивационных компонентов деятель- } \\
\text { ности. 2) Значение само по себе выполняет в познавательной деятельности функцию эталонизиро- } \\
\text { ванной операции, или, лучше сказать, «алгоритма категоризации» }{ }^{* * * *} \text {. }\end{array}$ \\
\hline В.П. Серкин & $\begin{array}{l}\text { Значение - образующая сознания, являющаяся субъективной формой отражения индивидуального } \\
\text { и общественно-исторического опыта, приобретенного в процессе личной истории индивидуальных и } \\
\text { совместных деятельностей }{ }^{* * * *} \text {. }\end{array}$ \\
\hline
\end{tabular}

* Выготский Л.С. Собр. соч. В 6-ти т. Т. 6. Научное наследство / Под ред. М.Г. Ярошевского. М.: Педагогика, 1984. С. 52.

** Леонтьев А.Н. Избранные психологические произведения: В 2-х т. М.: Педагогика, 1983. Т. 1. С. 290.

*** Петренко В.Ф. Психосемантика сознания. М.: ИМ УН-та, 1988, С. 10-11.

**** Шмелев А.Г. Концепция систем значений в экспериментальной психосемантике // Вопросы психологии. 1983 . № 4. С. 21. ***** Серкин В.П. Виды. Формы и новое определение понятия «значение» // Ученые записки кафедры психологии СВГУ. Магадан: Изд-во СВГУ, 2009. Вып. 7. С. 85-100.

ные теории» ${ }^{11}$. Моделирование систем значений предполагает создание системы, которая, описывает или воспроизводит объект исследования (социально-психологический феномен), например феномен экстремизма. Данное моделирование помогает реконструировать качественную специфику феномена, получить количественные характеристики, проинтерпретировать и прогнозировать возможные изменения.

Психосемантические методы реконструируют имплицитные теории личности и решают следующие задачи: соединение исследуемого значения данного явления с другими значениями, системами значений, выделение и интерпретация среди этих связей наиболее существенных, значимых и реконструирование модели данного явления ${ }^{12}$. Под реконструированием понимают воспроизведение социально психологических феноменов, происходивших в прошлом, на основе некоторой модели. Как пишет Е.Ю. Артемьева психосемантические методы «апеллируют к способности человека рефлексировать свое отношение к объектам, ситуаци-

11 Петренко В.Ф. Многомерное сознание: психосемантическая парадигма. М.: Новый хронограф, 2009. 440 с.

12 Серкин В.П. Методы психологии субъективной семантики и психосемантики. М.: Аспект Пресс, 2004. 207 с. ям, явлениям мира и ... к понятиям, существующим в естественном языке» ${ }^{13}$.

В основе психосемантических методов лежит процедура оценивания (шкалирование), в результате которой респондент выносит свое мнение о сходстве или различии анализируемых объектов (феноменов). Далее строятся массивы данных отражающие опыт, знания, представления в конкретной содержательной области, которые затем объединятся в общегрупповые матрицы и обрабатываются при помощи различных математических методов. Основной метод психосемантики, выявляющий скрытые (неосознаваемые) процессы - это метод построения семантических пространств (модельное представление) категориальных структур изучаемого феномена. Семантические пространства представляют собой операциональную модель категориальной структуры сознания. Эта модель изображается в виде математического пространства, где координатные оси выражают основания категоризации, координатные точки - это значения описываемой содержательной области. В семантическом пространстве реконструируется система значений описываемого явления, феномена.

13 Артемьева Е.Ю. Основы психологии субъективной семантики / Под ред. И.Б. Ханиной. М.: Наука; Смысл, 1999. 410 с. 


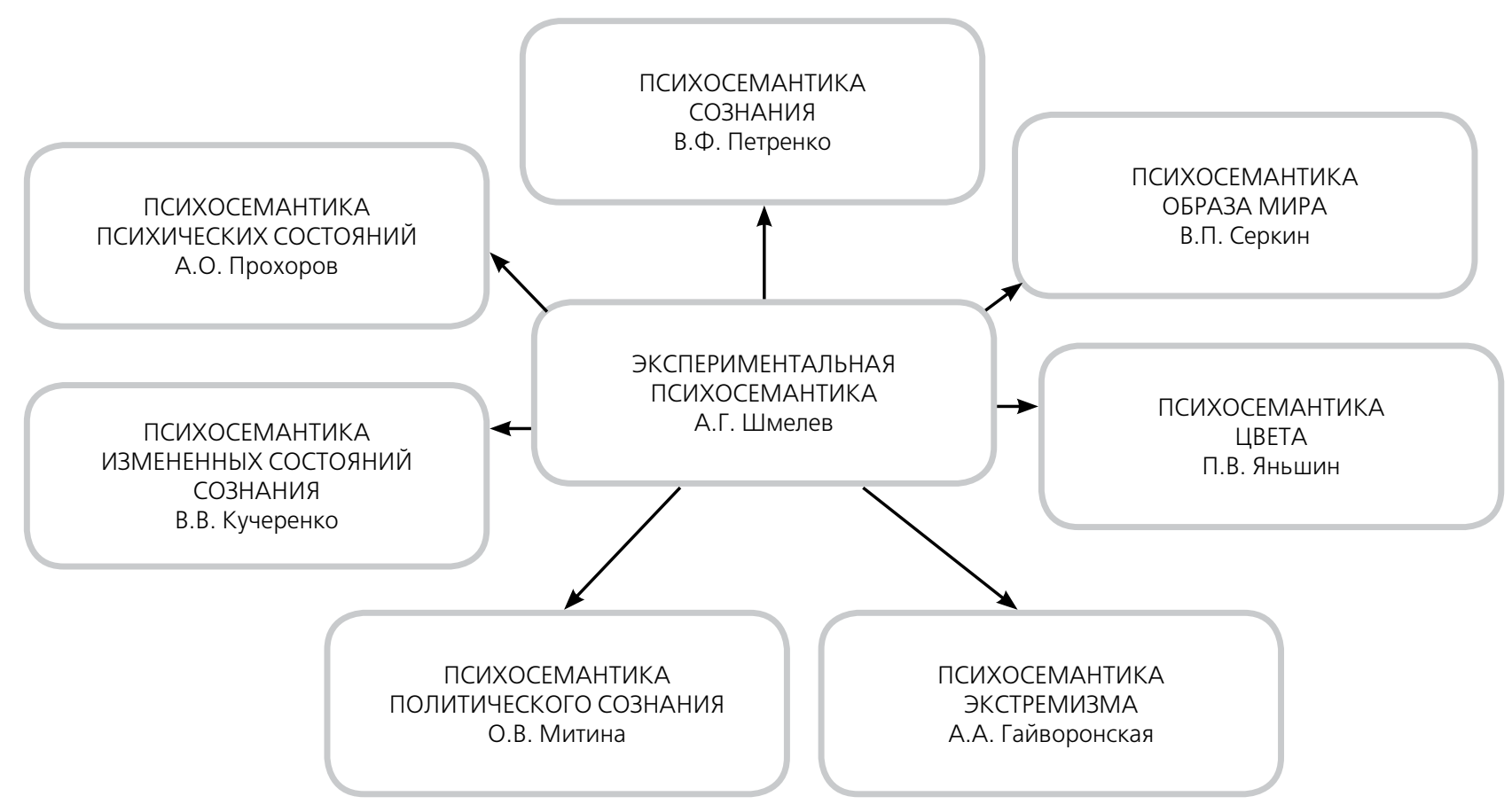

Рис. 1. Направления психосемантических исследований

В психосемантике проявляются междисциплинарные связи с другими науками, отраслями психологии - это и философия (категориальная структура сознания В.С. Степин), и культурология (категории средневековой культуры А.Я. Гуревич), языкознание (модель Смысл-текст И.А. Мельчук, лексическая семантика Ю.Д. Апресяна), социология (работы Т.С. Барановой), синергетика и др. А также психосемантика взаимосвязана с общей психологией, психологией восприятия, мышления, психических состояний, социальной психологией, этнической, гендерной, возрастной и др. Эти взаимосвязи нашли отражение в исследованиях О.В. Митиной и В.В. Кучеренко (процессы категоризации в измененных состояниях сознания).

В психологических исследованиях выделяется ряд направлений, в которых используется психосемантика или психосемантический инструментарий (см. рис. 2).

Например, исследования А.Г. Шмелев (Психосемантика и психодиагностика личности), П.В. Яньшина (Психосемантический анализ категоризации цвета в структуре сознания субъекта), О.В. Митина (Психосемантический анализ политического сознания), В.В. Кучеренко (Процессы категоризации в измененных состояниях сознания), В.П. Серкин (Структура и функции образа мира в практической деятельности), А.О. Прохоров (Психосемантика психических состояний) и др.

Мы полагаем, что существует необходимость проведения исследований психосемантическими методами феномена экстремизма, так как в психологической науке в целом существует противоречивая ситуация вокруг дефиниции «экстремизм». Большое количество исследователей предлагает объяснение этого феномена с разных точек зрения. Например, Л.Н. Аксеновская считает, что экстремизм - это психосоциокультурный феномен, объективная оценка которого осуществляется на базе критерия социальных и социопсихологических последствий, вызываемых экстремистскими действиями социальных групп, группировок и индивидов ${ }^{14}$. Для С.Б. Целиковского экстремизм - это стилевая характеристика личности, которая определяет высокую вероятность выбора крайних точек зрения, способов достижения выбранных целей ${ }^{15}$. Су-

\footnotetext{
14 Аксеновская Л.Н. Экстремизм: смысл и результат (ордерный аспект) // Экстремизм и средства массовой информации. Материалы Всероссийской научно-практической конференции / Под ред. В.Е. Семенова. СПб.: Астерион, 2006.

15 Целиковский С.Б. О психологических и идеологических предпосылках радикализма, экстремизма, терроризма //
} 


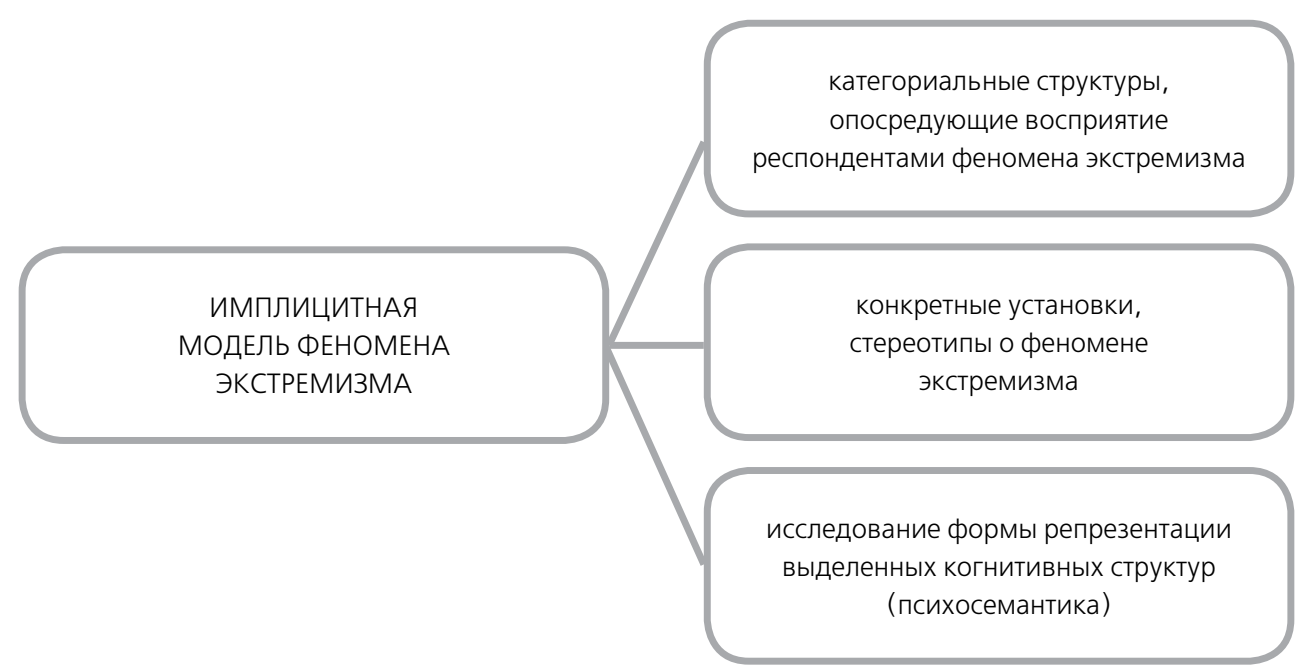

Таблица 2. Имплицитная модель феномена экстремизма на основе психосемантики

ществует и другая точка зрения на этот феномен. По мнению Э. Стахельски, можно сформировать экстремисткое сознание. Для этого надо выполнить деплюрализацию (лишение всех групповых идентичностей), деиндивидуацию себя (лишение личной идентичности), деиндивидуацию других (лишение врагов их личных идентичностей), дегуманизацию (идентифицирование врагов как недочеловеков или нелюдей) и демонизацию (идентифицирование врагов как зла) ${ }^{16}$. На наш взгляд рассмотрение феномена экстремизма связано с изучением важнейших компонентов ценностносмысловых ориентаций, установок, стереотипов различных социальных, возрастных или этнических групп. Изучение психосемантики экстремизма поможет реконструировать имплицитные картины феномена экстремизма. Мы полагаем что, можно сформулировать следующее, пока еще предварительное, утверждение: существует психологическая (семантическая) структура феномена экстремизма, сформированная различными типами значений, категориальными структурами, «классифищирующими» этот феномен, его виды на разных уровнях взаимодействия с субъектом или группой.

Объект психосемантики экстремизма - это системы значений, описывающие данный феномен. Эти системы значений выражают характери-

Научные ведомости БелГУ. Сер. Гуманитарные науки. 2009. № 14. Вып. 4/1. С. 123-129.

16 Stahelski A. Terrorists Are Made, Not Born: Creating Terrorists Using Social Psychological Conditioning. Journal of Homeland Security. March, 2004. стики феномена экстремизма, его проявления в сознании субъектов. Предметом психосемантики экстремизма является моделирование систем значений описывающих этнический, религиозный, политический экстремизм, а также реконструирование семантических пространств, представляющих данный феномен.

Задача психосемантики экстремизма - это реконструкция системы категорий, которыми пользуется общественное сознание при восприятии феномена экстремизма. Иными словами для реконструкции имплицитной модели феномена экстремизма необходимо:

1. Объяснение категориальных структур, опосредующих восприятие респондентами феномена экстремизма;

2. Анализ конкретных установок, стереотипов о феномене экстремизма;

3. Метод исследования и форма репрезентации выделенных когнитивных структур выступает психосемантика (см. табл. 2).

Методы психосемантики, а именно, метод множественной идентификации, микросемантичсекий анализ, семантический дифференциал и др. способствуют объяснению тех категориальных структур, которые опосредуют восприятие и осознание феномена экстремизма. Количество полученных факторов показывает когнитивную сложность респондентов принявших участие в исследовании, содержание и мощность выделяемых факторов (вклад фактора в общую дисперсию) представляет присущие субъекту (респонденту) формы категоризации и их субъективную значимость. 
Семантические пространства выступают операциональными моделями данных структур сознания описывающих феномен экстремизма.

На основании всего выше сказанного, считаем, что, психосемантика экстремизма способствует более тщательному изучению сущностных характеристики феномена экстремизма, а именно, как системы значений выражаясь в различных контекстах, проявляются на бессознательном и осознанном уровне применительно к феномену экстремизма и его видам.

\section{Список литературы:}

1. Аксеновская Л.Н. Экстремизм: смысл и результат (ордерный аспект) // Экстремизм и средства массовой информации. Материалы Всероссийской научно-практической конференции / Под ред. В.Е. Семенова. СПб.: Астерион, 2006.

2. Артемьева Е.Ю. Основы психологии субъективной семантики / Под ред. И.Б. Ханиной. М.: Наука; Смысл, 1999. $410 \mathrm{c}$.

3. Борисов С.В. Проблемы формирования международно-правовых понятий экстремизма и преступлений экстремистской направленности // Союз криминалистов и криминологов. 2013. № 2. С. 54-59.

4. Васнецова А.С. Ваххабизм в России: характеристика, взаимосвязь с терроризмом и экстремизмом, перспективы государственного регулирования // NB: Проблемы общества и политики. 2013. № 11. С. 154201. (URL: http://www.e-notabene.ru/pr/article_10185.html).

5. Выготский Л.С. Собрание сочинений: В 6-ти т. Т. 6. Научное наследство / Под ред. М.Г. Ярошевского. М.: Педагогика, 1984.

6. Гайворонская А.А. Экстремизм как объект социально-психологического исследования // Психология и психотехника. 2012. № 1. С. 72-80.

7. Леонтьев А.Н. Избранные психологические произведения: В 2-х т. Т. І. М.: Педагогика, 1983.

8. Леонтьев А.Н. Образ мира // Леонтьев А.Н. Избранные психологические произведения: В 2-х т. М., 1983. C. 251-261.

9. Леонтьев Д.А. Мировоззрение как миф и мировоззрение как деятельность // Менталитет и коммуникативная среда в транзитивном обществе / Под ред. В.И. Кабрина и О.И Муравьевой. Томск: Томский государственный университет, 2004. С. 11-29.

10. Никольская А.В. Социально-психологические аспекты межвидового взаимодействия // Психология и психотехника. 2012. № 7. С. 48-54.

11. Ноянзина О.Е., Гончарова Н.П., Авдеева Г.С. Этнополитический экстремизм как угроза национальной безопасности России // Национальная безопасность. 2012. № 2. С. 76-87.

12. Омарова З.У., Якубова С.З. Религиозно-политический экстремизм: идеология противодействия // Политика и общество. 2011. № 10. С. 22-26.

13. Петренко В.Ф. Многомерное сознание: психосемантическая парадигма. М.: Новый хронограф, 2009. 440 c.

14. Петренко В.Ф. Психосемантика сознания. М.: ИМ Ун-та, 1988.

15. Петренко В.Ф. Психосемантические аспекты картины мира субъекта // Психология. Журнал Высшей школы экономики. 2005. Т. 2. № 2. С. 3-23.

16. Серкин В.П. Виды. Формы и новое определение понятия «значение» // Ученые записки кафедры психологии СВГУ. Магадан: Изд-во СВГУ, 2009. Вып. 7. С. 85-100.

17. Серкин В.П. Методы психологии субъективной семантики и психосемантики. М.: Аспект Пресс, 2004.

18. Словарь / Под ред. М.Ю. Кондратьева // Психологический лексикон. Энциклопедический словарь в 6-ти томах / Ред.-сост. Л.А. Карпенко; Под общ. ред. А.В. Петровского. М.: ПЕР СЭ, 2006. 176 с.

19. Словарь практического психолога / Сост. С.Ю. Головин. Минск: Харвест; 1998. 800 с.

20. Целиковский С.Б. О психологических и идеологических предпосылках радикализма, экстремизма, терроризма // Научные ведомости БелГУ. Сер. Гуманитарные науки. 2009. № 14. Вып. 4/1. С. 123-129.

21. Шмелев А.Г. Концепция систем значений в экспериментальной психосемантике // Вопросы психологии. 1983. № 4. С. 21.

22. Bruner J.S., Tagiuri R. The perception of people // Handbook of Social Psychology. N.J., 1954.

23. Perffetti Ch. Psychosemantics: Some cognitive aspects of structural meaning // Psychol. Bull., 1972, v. 78, № 4, pp. 241-259. 


\section{Психология и психотехника 4(67) • 2014}

24. Stahelski A. Terrorists Are Made, Not Born: Creating Terrorists Using Social Psychological Conditioning. Journal of Homeland Security, March, 2004.

\section{References (transliteration):}

1. Aksenovskaya L.N. Ekstremizm: smysl i rezul'tat (ordernyi aspekt) // Ekstremizm i sredstva massovoi informatsii. Materialy Vserossiiskoi nauchno-prakticheskoi konferentsii / Pod red. V.E. Semenova. SPb.: Asterion, 2006.

2. Artem'eva E.Yu. Osnovy psikhologii sub"ektivnoi semantiki / Pod red. I.B. Khaninoi. M.: Nauka; Smysl, 1999. $410 \mathrm{~s}$.

3. Borisov S.V. Problemy formirovaniya mezhdunarodno-pravovykh ponyatii ekstremizma i prestuplenii ekstremistskoi napravlennosti // Soyuz kriminalistov i kriminologov. 2013. № 2. S. 54-59.

4. Vasnetsova A.S. Vakhkhabizm v Rossii: kharakteristika, vzaimosvyaz' s terrorizmom i ekstremizmom, perspektivy gosudarstvennogo regulirovaniya // NB: Problemy obshchestva i politiki. 2013. № 11. S. 154201. (URL: http://www.e-notabene.ru/pr/article_10185.html).

5. Vygotskii L.S. Sobranie sochinenii: V 6-ti t. T. 6. Nauchnoe nasledstvo / Pod red. M.G. Yaroshevskogo. M.: Pedagogika, 1984.

6. Gaivoronskaya A.A. Ekstremizm kak ob"ekt sotsial'no-psikhologicheskogo issledovaniya // Psikhologiya i psikhotekhnika. 2012. № 1. S. 72-80.

7. Leont'ev A.N. Izbrannye psikhologicheskie proizvedeniya: V 2-kh t. T. I. M.: Pedagogika, 1983.

8. Leont'ev A.N. Obraz mira // Leont'ev A.N. Izbrannye psikhologicheskie proizvedeniya: V 2-kh t. M., 1983. S. 251-261.

9. Leont'ev D.A. Mirovozzrenie kak mif i mirovozzrenie kak deyatel'nost' // Mentalitet i kommunikativnaya sreda v tranzitivnom obshchestve / Pod red. V.I. Kabrina i O.I Murav'evoi. Tomsk: Tomskii gosudarstvennyi universitet, 2004. S. 11-29.

10. Nikol'skaya A.V. Sotsial'no-psikhologicheskie aspekty mezhvidovogo vzaimodeistviya // Psikhologiya i psikhotekhnika. 2012. № 7. S. 48-54.

11. Noyanzina O.E., Goncharova N.P., Avdeeva G.S. Etnopoliticheskii ekstremizm kak ugroza natsional'noi bezopasnosti Rossii // Natsional'naya bezopasnost'. 2012. № 2. S. 76-87.

12. Omarova Z.U., Yakubova S.Z. Religiozno-politicheskii ekstremizm: ideologiya protivodeistviya // Politika i obshchestvo. 2011. № 10. S. 22-26.

13. Petrenko V.F. Mnogomernoe soznanie: psikhosemanticheskaya paradigma. M.: Novyi khronograf, $2009.440 \mathrm{~s}$.

14. Petrenko V.F. Psikhosemantika soznaniya. M.: IM Un-ta, 1988.

15. Petrenko V.F. Psikhosemanticheskie aspekty kartiny mira sub"ekta // Psikhologiya. Zhurnal Vysshei shkoly ekonomiki, 2005. T. 2. № 2. S. 3-23.

16. Serkin V.P. Vidy. Formy i novoe opredelenie ponyatiya «znachenie» // Uchenye zapiski kafedry psikhologii SVGU. Magadan: Izd-vo SVGU, 2009. Vyp. 7. S. 85-100.

17. Serkin V.P. Metody psikhologii sub"ektivnoi semantiki i psikhosemantiki. M.: Aspekt Press, 2004.

18. Slovar' / Pod. red. M.Yu. Kondrat'eva // Psikhologicheskii leksikon. Entsiklopedicheskii slovar' v shesti tomakh / Red.-sost. L.A. Karpenko; Pod obshch. red. A.V. Petrovskogo. M.: PER SE, 2006. 176 s.

19. Slovar' prakticheskogo psikhologa / Sost. S.Yu. Golovin. Minsk: Kharvest; 1998. 800 s.

20. Tselikovskii S.B. O psikhologicheskikh i ideologicheskikh predposylkakh radikalizma, ekstremizma, terrorizma // Nauchnye vedomosti BelGU. Ser. Gumanitarnye nauki. 2009. № 14. Vyp. 4/1. S. 123-129.

21. Shmelev A.G. Kontseptsiya sistem znachenii v eksperimental'noi psikhosemantike // Voprosy psikhologii. 1983. № 4. S. 21.

22. Bruner J.S., Tagiuri R. The perception of people // Handbook of Social Psychology. N.J., 1954.

23. Perffetti Ch. Psychosemantics: Some cognitive aspects of structural meaning // Psychol. Bull., 1972, v. 78, № 4, pp. 241-259.

24. Stahelski A. Terrorists Are Made, Not Born: Creating Terrorists Using Social Psychological Conditioning. Journal of Homeland Security, March, 2004. 